\title{
Self-Assembly of ATRP-Synthesized PCH-b-PtBA-b-PCH Triblock Copolymers Observed by Time-Resolved SAXS
}

\author{
Alexandra Muñoz-Bonilla, María L. Cerrada, Marta Fernández-García*
}

The phase behavior of PCH-b-PtBA-b-PCH triblock copolymers has been studied. Measurements in the wide-angle region probed the existence of microphase segregation through variation of block mobility and thermal expansion coefficients. SAXS experiments pointed out that most copolymers present ordered nanostructures, mostly hexagonally packed cylinders, the morphology being confirmed by AFM. An unusual disorder-to-order transition is observed in one copolymer synthesized from a macroinitiator with intermediate length and the highest outer-block molecular weight, whereas none of the copolymers shows an order-to-disorder transition upon heating over the temperature range analyzed.

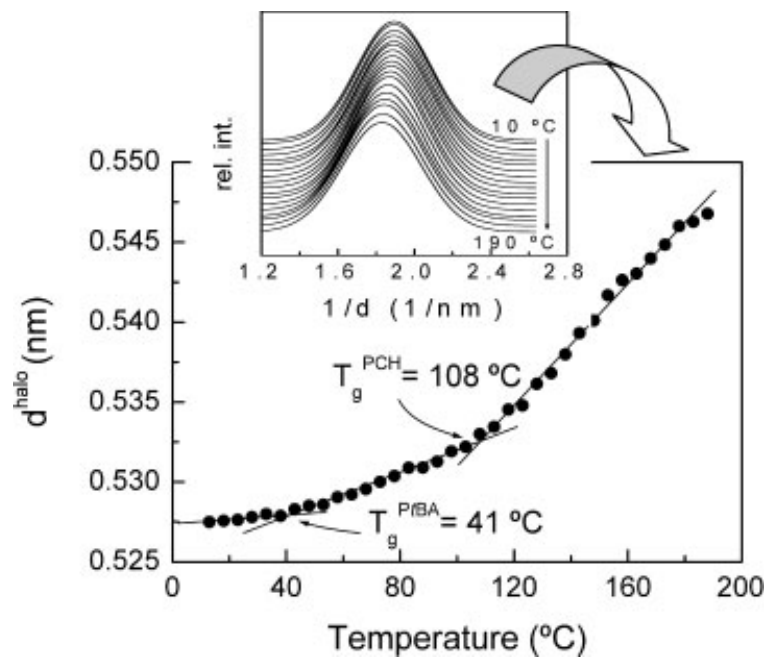

\section{Introduction}

Block copolymers have been recognized as advanced nanomaterials because they can self-assemble into various patterns with periodicity in the condensed state as well as in solution (spheres, cylinders, lamellae, or bicontinuous double diamonds, depending on the volume fraction of the block components, the difference in their solubility parameters, sample preparation, and thermal history ${ }^{[1]}$ ) and can be used as templates towards advanced practical applications. $^{[2-4]}$

The recent development of controlled free radical polymerization techniques, ${ }^{[5-7]}$ and more distinctively atom

A. Muñoz-Bonilla, M. L. Cerrada, M. Fernández-García Instituto de Ciencia y Tecnología de Polímeros (CSIC) C/Juan de la Cierva 3, 28006 Madrid, Spain

E-mail: martafg@ictp.csic.es transfer radical polymerization (ATRP), ${ }^{[8]}$ has allowed the synthesis of block copolymers with controlled molecular weights and low polydispersity indexes. In addition, a better control of the structure may require information on the process and kinetics of the phase transitions of the block copolymers, such as the order-to-disorder transition (ODT) and the order-to-order transition (OOT), ${ }^{[9-11]}$ which enables the morphology to be controlled by changing the temperature without varying the block copolymer composition.

Few block copolymers ${ }^{[12-17]}$ undergo a transition from a phase-mixed to other phase-separated states upon heating, referred to as the lower disorder-to-order transition (LDOT). This occurs when the thermal expansion, the so-called free volume effect, dominates the reduction in the enthalpic repulsive energy.

Small-angle X-ray scattering (SAXS) is a powerful tool to study phase separation processes in block copolymers and 
to determine microdomain sizes. The combination of SAXS results with those obtained by atomic force microscopy (AFM) allows a more reliable establishment of the block morphology.

The synthesis of well-defined triblock copolymers by the ATRP of tert-butyl acrylate (tBA) as an inner block with cyclohexyl methacrylate $(\mathrm{CH})$ as outer segments, i.e., poly(cyclohexyl methacrylate)-block-poly(tert-butyl acrylate)-block-poly(cyclohexyl methacrylate) (PCH-b-PtBA-b$\mathrm{PCH}$ ) copolymers, has been reported ${ }^{[18]}$ in a previous work. DSC measurements showed almost complete phase segregation between the blocks since the location of the single glass transition detected, which was associated with cooperative motions of the outer blocks $\left(T_{\mathrm{g}}^{\mathrm{PCH}}\right)$, was very similar to that observed in the corresponding $\mathrm{PCH}$ homopolymer. This article describes the morphology assignment found within these triblock copolymers by means of results obtained by SAXS experiments, using a mono or bidimensional detector, together with those attained by AFM. The existence of phase separation in block copolymers has been probed by wide-angle time-resolved temperature-variable X-ray scattering (WAXS) measurements for the first time, to the best of our knowledge. All of these PCH-b-PtBA-b-PCH ATRPsynthesized copolymers have been analyzed considering the global composition, the PtBA macroinitiator length, and the molecular weight of the PCH outer segments.

\section{Experimental Part}

Difunctional $\alpha, \omega$-dibromopoly(tert-butyl acrylate) macroinitiators of different chain lengths were synthesized in bulk by ATRP from $t \mathrm{BA}$. Once these macroinitiators were prepared, $\mathrm{PCH}_{X}-b-\mathrm{P}_{\mathrm{BA}}-b$ $\mathrm{PCH}_{X}$ triblock copolymers were then synthesized in a sequential manner by ATRP with different chain lengths of the inner tBA segments and the outer PCH segments in 50 vol.-\% toluene solutions with an exchange halide macroinitiator/catalyst system $([\mathrm{CH}] /[\mathrm{Br}-\mathrm{PtBA}-\mathrm{Br}] /[\mathrm{CuCl}] /[\mathrm{PMDETA}]=800: 1: 1: 1) \cdot{ }^{[18]}$ Table 1 summarizes the morphological characteristics found in the different $\mathrm{PCH}-b$-PtBA- $b$-PCH copolymers synthesized for the present study. The subscripts that follow the label ascribed to each block are related to their corresponding degree of polymerization.

\section{Specimen Preparation}

On the one hand, copolymer films were prepared by casting from 8 vol.-\% toluene solution for X-ray measurements. On the other hand, thin-films of each copolymer were obtained from toluene solutions $\left(5 \mathrm{mg} \cdot \mathrm{mL}^{-1}\right)$ by spin-coating onto supported mica for AFM measurements. To further promote the formation of equilibrium morphologies within both types of films, they were annealed under vacuum at $130^{\circ} \mathrm{C}$ for $72 \mathrm{~h}$. The films were then slowly cooled to room temperature.
Table 1. Cyclohexyl methacrylate weight fraction in the copolymer, $w^{\mathrm{CH}}$, types of nanostructure developed at $10^{\circ} \mathrm{C}$ after a previous heating/cooling cycle, and a characteristic domain spacing determined from SAXS experiments.

\begin{tabular}{|c|c|c|c|}
\hline \multirow[t]{2}{*}{ Copolymer } & \multirow[t]{2}{*}{$w^{\mathrm{CH}}$} & \multirow[t]{2}{*}{ Morphology } & \multirow{2}{*}{$\frac{d^{\mathrm{a})}}{\mathrm{nm}}$} \\
\hline & & & \\
\hline $\mathrm{PCH}_{81}-b-\mathrm{PtBA} \mathrm{B}_{107}-b-\mathrm{PCH}_{81}$ & 0.664 & HEX & 41.5 \\
\hline $\mathrm{PCH}_{113}-b-\mathrm{PtBA} \mathrm{A}_{107}-b-\mathrm{PCH}_{113}$ & 0.735 & HEX & 49.5 \\
\hline $\mathrm{PCH}_{221}-b-\mathrm{PtBA}_{107}-b-\mathrm{PCH}_{221}$ & 0.844 & - & - \\
\hline $\mathrm{PCH}_{276}-b-\mathrm{PtBA} \mathrm{B}_{107}-b-\mathrm{PCH}_{276}$ & 0.872 & - & - \\
\hline $\mathrm{PCH}_{33}-b-\mathrm{PtBA} \mathrm{B}_{147}-b-\mathrm{PCH}_{33}$ & 0.368 & $\mathrm{BCC}$ & 60.0 \\
\hline $\mathrm{PCH}_{84}-b-\mathrm{PtBA}_{147}-b-\mathrm{PCH}_{84}$ & 0.599 & HEX & 31.2 \\
\hline $\mathrm{PCH}_{123}-b-\mathrm{PtBA} 147-b-\mathrm{PCH}_{123}$ & 0.687 & HEX & 35.1 \\
\hline $\mathrm{PCH}_{216}-b-\mathrm{PtBA} \mathrm{B}_{147}-b-\mathrm{PCH}_{216}$ & 0.794 & HEX & 40.9 \\
\hline $\mathrm{PCH}_{219}-b-\mathrm{PtBA}_{147}-b-\mathrm{PCH}_{219}$ & 0.796 & HEX & 42.3 \\
\hline $\mathrm{PCH}_{260}-b-\mathrm{PtBA} \mathrm{B}_{147}-b-\mathrm{PCH}_{260}$ & 0.822 & HEX & 38.6 \\
\hline $\mathrm{PCH}_{174}-b-\mathrm{PtBA} 213-b-\mathrm{PCH}_{174}$ & 0.683 & HEX & 37.5 \\
\hline $\mathrm{PCH}_{248}-b-\mathrm{PtBA} 213-b-\mathrm{PCH}_{248}$ & 0.754 & HEX & 39.4 \\
\hline $\mathrm{PCH}_{260}-b-\mathrm{PtBA} \mathrm{B}_{213}-b-\mathrm{PCH}_{260}$ & 0.763 & HEX & 36.6 \\
\hline $\mathrm{PCH}_{315}-b-\mathrm{PtBA}_{213}-b-\mathrm{PCH}_{315}$ & 0.796 & HEX & 37.3 \\
\hline $\mathrm{PCH}_{342}-b-\mathrm{PtBA}_{213}-b-\mathrm{PCH}_{342}$ & 0.809 & HEX & 35.7 \\
\hline
\end{tabular}

a) The domain spacing for sphere and hexagonally packed patterns were determined as $\left(2 \pi / q^{*}\right)(3 / 2)^{1 / 2}$ and $\left(2 \pi / q^{*}\right)(4 / 3)^{1 / 2}$, respectively.

\section{SAXS}

The morphologies developed in the annealed $\mathrm{PCH}_{X}-b-\mathrm{PtBA}_{Y}-b$ $\mathrm{PCH}_{X}$ copolymers with different compositions, macroinitiator lengths, and outer PCH molecular weights were analyzed by time-resolved SAXS measurements using synchrotron radiation in the A2 Soft Condensed Matter beamline of Hasylab at DESY (Hamburg, Germany), working at a wavelength of $0.150 \mathrm{~nm}$. Simultaneous WAXS patterns were recorded to explore the feasibility of determining the existence of phase separation. Two different setups were utilized. In the first one, two linear position-sensitive detectors were used simultaneously, one of them at about $280 \mathrm{~cm}$ from the sample (which was inside the temperature controller of the beamline), covering the SAXS region, and the other at around $25 \mathrm{~cm}$ from the sample ranging, approximately, in the $2 \theta$ WAXS region from 10 to $25^{\circ}$. The WAXS detector was calibrated with the distinct diffractions of a triclinic semicrystalline poly(ethylene terephthalate) (PET) sample, and the SAXS detector was calibrated with the different orders of the long spacing of a rat-tail cornea $(L=65 \mathrm{~nm})$. A scanning rate of $10^{\circ} \mathrm{C} \cdot \mathrm{min}^{-1}$ was used for the different applied temperature scans, and frames were acquired every $30 \mathrm{~s}$. The rate used is relatively high because of the limited synchrotron beam time. All experiments comprised the heating of the initial annealed sample from 10 to $190^{\circ} \mathrm{C}$ followed by its cooling and a subsequent heating run. Profiles were normalized for the intensity of the primary beam and the scattering of an empty sample was subtracted. 
In the second setup, a MAR CCD detector, at a distance of $260 \mathrm{~cm}$ from the sample, was utilized to confirm the one-dimensional (1D) recorded SAXS results since the combination of synchrotron radiation with two-dimensional (2D) detection makes it possible to observe more clearly the weak scattering peaks, which would otherwise be difficult to correctly assign. Therefore, 2D SAXS images were integrated $360^{\circ}$ azimuthally to verify the position of the weak high-order diffractions. A rat-tail cornea specimen was again used for calibration. A heating rate of $10^{\circ} \mathrm{C} \cdot \mathrm{min}^{-1}$ was employed, and images were acquired every $30 \mathrm{~s}$ from 10 to $190^{\circ} \mathrm{C}$. The 2D X-ray patterns were processed with the FIT2D program of Dr. Hammersley (ESRF), and converted into 1D arrays after normalization of the intensity of the primary beam and subtraction of the scattering of an empty sample.

\section{Atomic Force Microscopy (AFM)}

The surface morphology of the thin films was observed using tapping mode AFM (Multimode Nanoscope IVa, Digital Instrument/Veeco) under ambient conditions. In tapping mode, the stylus oscillates and touches the sample only at the end of its downward movement. The nominal resonance frequency for the tapping mode was between $265-309 \mathrm{kHz}$ with a phosphorous (n) doped Si cantilever which had a spring constant that ranged from 20 to $80 \mathrm{~N} \cdot \mathrm{m}^{-1}$. The set point in the AFM control program was adjusted to change the contact force between the tip and surface in order to detect the existence of morphologies.

\section{Results and Discussion}

The thermal analysis determined by DSC of the $\mathrm{PCH}_{X}-b$ $\mathrm{PtBA}_{Y}-b-\mathrm{PCH}_{X}$ triblock copolymers revealed that, although the glass transition corresponding to the PtBA macroinitiator was not observed, the microphase separation was almost complete in these ABA triblock copolymers because the glass transition temperature that related to the $\mathrm{PCH}$ blocks was very similar to that observed in the corresponding $\mathrm{PCH}$ homopolymer. In addition, this thermal characterization pointed out the amorphous nature of these copolymers. Therefore, the WAXS profiles that they exhibit consist of a single amorphous halo with the absence of other diffraction peaks, as seen in Figure 1(a) for the $\mathrm{PCH}_{276}-b-\mathrm{PtBA} \mathrm{B}_{107}-b-\mathrm{PCH}_{276}$ copolymer. In spite of the relative simplicity of the patterns in the wide-angle region, the detailed assessment of the variation with temperature of the amorphous halo peak, whose position in the maximum ( $d^{\text {halo }}$ ) is directly ascribed to the most probable intermolecular distance between macromolecular chains, ${ }^{[19]}$ provides important quantitative information on the existence of microphase separation in these ABA copolymers. As depicted in Figure 1 (b) for $\mathrm{PCH}_{276}-b$ $\mathrm{PtBA}_{107}-b-\mathrm{PCH}_{276}$, at the lowest temperatures, from $10^{\circ} \mathrm{C}$ to around $40^{\circ} \mathrm{C}$, the location of the amorphous halo
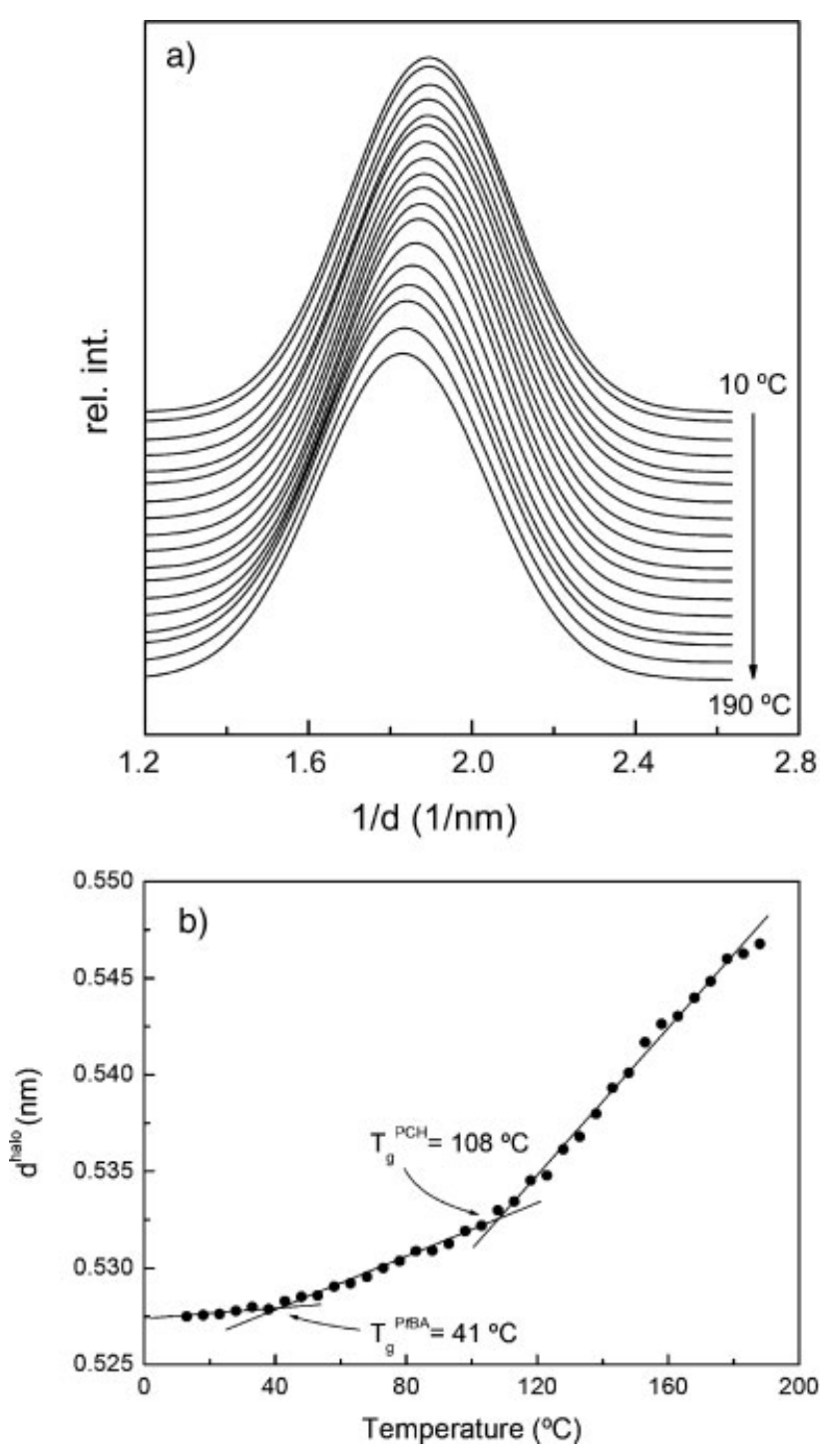

Figure 1. (a) Time-resolved WAXS profiles for $\mathrm{PCH}_{276}-b-\mathrm{PtBA}_{107}-b$ $\mathrm{PCH}_{276}$ triblock copolymer during the first heating process and (b) dependence of $d^{\text {halo }}$ on temperature.

maximum varies very subtly because of the small motion capability of the whole block copolymer since both inner and outer segments are below their corresponding glass transition temperatures and, consequently, they are in their respective glassy states. Once the inner block gains mobility at temperatures higher than about $40^{\circ} \mathrm{C}$, the $T_{\mathrm{g}}^{\text {PtBA}}$, the position of the most probable intermolecular distance between macromolecules is moved to lower $1 / d$ values and, consequently, higher $d^{\text {halo }}$ spacings. Therefore, its temperature coefficient gradually increases up to around $110^{\circ} \mathrm{C}$, i.e., the $T_{\mathrm{g}}^{\mathrm{CH}}$, and more abruptly from that to the final empirical temperature measured $\left(190^{\circ} \mathrm{C}\right)$, which is attributable to the capability of cooperative and generalized motions within macromolecules of this block copolymer because of its elastomeric state at these 

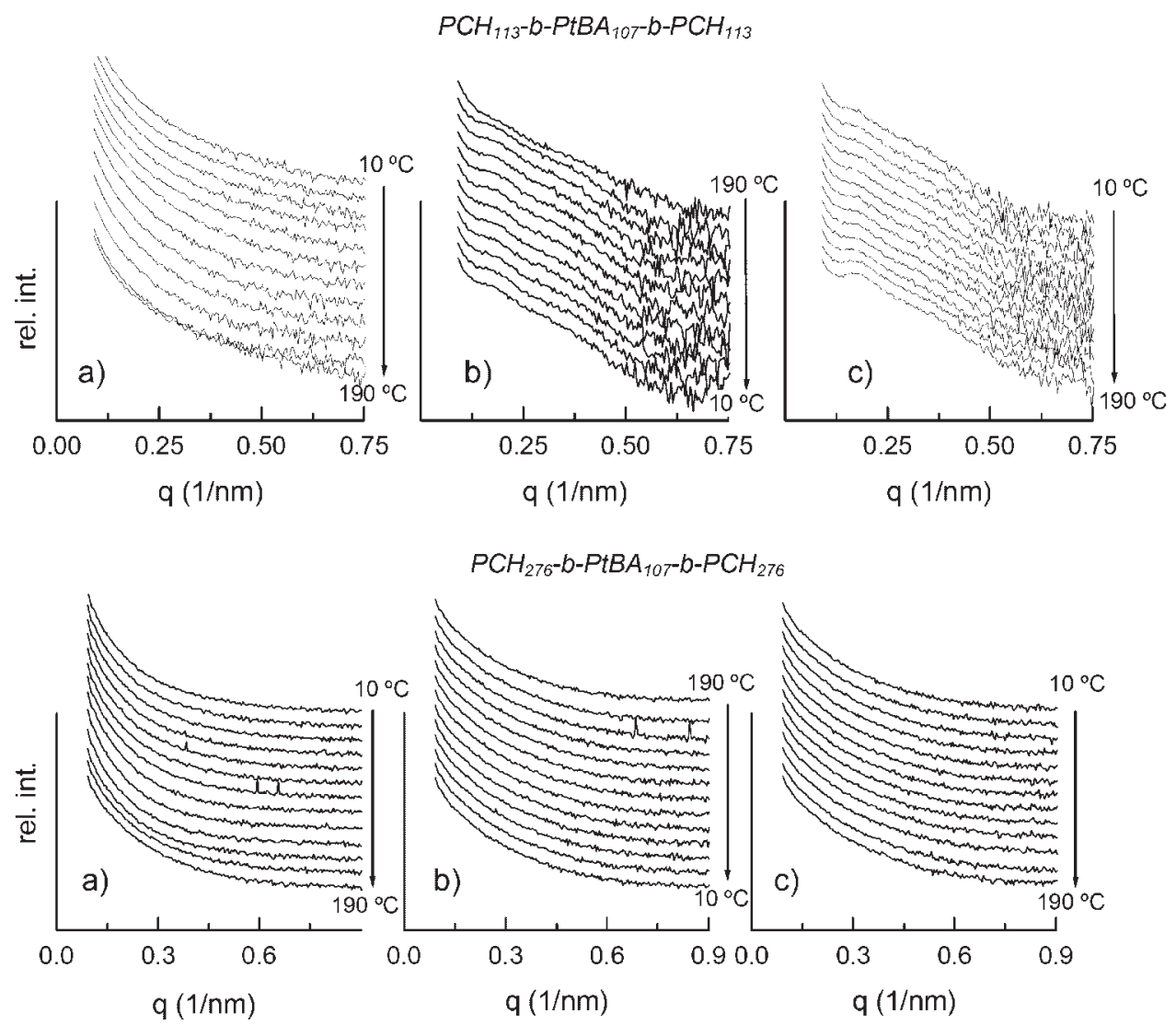

Figure 2. Time-resolved SAXS profiles of $\mathrm{PCH}_{113}-b-\mathrm{PtBA}_{107}-b-\mathrm{PCH}_{113}$ and $\mathrm{PCH}_{276}-b-\mathrm{PtBA}_{107}-b-\mathrm{PCH}_{276}$ triblock copolymers as a function of scattering vector: (a) first heating, (b) cooling, and (c) second heating.

high temperatures. Accordingly, the glass transition temperatures of each individual block, i.e., the inner and outer PtBA and PCH segments, respectively, can be determined from the intersections of these different slopes (fits to straight lines are represented in Figure 1(b)), which are associated with the change of thermal expansion coefficients and, thus, to the variation of the copolymer mobility. The agreement with the $T_{\mathrm{g}}$ values obtained by $\mathrm{DSC}^{[18]}$ for the PtBA macroinitiator and outer blocks is extremely good and confirms the microphase separation of these ABA triblock copolymers.

The microdomains that exist in a block copolymer, when phase separation occurs, ${ }^{[9]}$ can be randomly distributed or, in other cases, may form a regular arrangement that gives rise to a periodic structure that usually generates profiles in the small-angle $X$ ray region. Therefore, the SAXS profile analysis allows, if the electron density contrast is high enough, identification of the morphology developed. Figure 2 shows, for two of the $\mathrm{PCH}_{X}-b-\mathrm{PtBA}_{Y}-b-\mathrm{PCH}_{X}$ triblock copolymers with the shortest inner PtBA block length, the variation with temperature of the scattered radiation intensity versus the magnitude of the scattering vector, $q$, this being defined as:

$$
q=\frac{4 \pi \sin \theta}{\lambda}
$$

where $2 \theta$ is the scattering angle and $\lambda$ is the wavelength. The profiles ascribed to $\mathrm{PCH}_{113}-b-\mathrm{PtBA}_{107}-b-\mathrm{PCH}_{113}$ are represented in the upper part of Figure 2. A monotonic drop of the intensity that reaches the SAXS detector is observed but no scattering peak appears during the first heating run, probably because of the disorder that exists between the inner and outer blocks and because of the small electron density contrast between both of them. However, with subsequent cooling, nascent peaks begin to become visible, and become more evident as the temperature diminishes. Therefore, a disorder-to-order transition upon cooling seems to take place in this block copolymer although the block arrangement developed is quite imperfect. This not well-defined morphology is slightly improved further during the second heating, which shows that the spatial concentration fluctuation of the block copolymer segments seems to deviate from the 
sinusoidal-wave-type fluctuation characteristic of the weak segregation limit, and to generate a certain longrange spatial order extremely defective. The primary maximum peak position, $q^{*}$, allows estimation of the Bragg spacing, $d$, through Bragg's law:

$$
q *=\frac{2 \pi}{d}
$$

where $d$ is the periodicity or spacing. The $\mathrm{PCH}_{113}-b$ $\mathrm{P} \mathrm{BA}_{107}-b-\mathrm{PCH}_{113}$ copolymer exhibits a Bragg spacing of $42.9 \mathrm{~nm}$ at ambient temperature after the first heating and its subsequent cooling at $10^{\circ} \mathrm{C} \cdot \mathrm{min}^{-1}$. The spacing is lowered for the $\mathrm{PCH}_{81}-b-\mathrm{P}_{\mathrm{B}} \mathrm{B}_{107}-b-\mathrm{PCH}_{81}$ copolymer with the lowest molecular weight in the outer PCH blocks. In the temperature range analyzed the order-to-disorder transition on heating is not observed for these two copolymers. An enlargement of the temperature interval evaluated has not been considered appropriate since these block copolymers might degrade, which would change their chemical structures and lead to misleading results.

However, no scattering peaks are observed in the time-resolved profiles for the copolymers with the same low-molecular-weight macroinitiator but with higher molecular weight outer blocks. The $\mathrm{PCH}_{276}-b-\mathrm{PtBA}_{107}-b-$ $\mathrm{PCH}_{276}$ copolymer is represented in the lower pictures of Figure 2 for the three temperature-variable processes analyzed: first heating, cooling, and second heating. This characteristic seems to point out, i) that the microdomains are disorderly allocated and are not able to gain any order with thermal treatment, in spite of the existence of phase separation as estimated by DSC and WAXS, and ii) that fluctuations of electronic density between segregated phases become even smaller than for $\mathrm{PCH}_{81}-b-\mathrm{PtBA}_{107}-b$ $\mathrm{PCH}_{81}$ and $\mathrm{PCH}_{113}-b-\mathrm{PtBA}_{107}-b-\mathrm{PCH}_{113}$, probably because of the greater difference between the molecular weights of both the inner an outer blocks. The $\mathrm{PCH}_{221}-b-\mathrm{P}_{\mathrm{BAA}} \mathrm{B}_{107}-b$ $\mathrm{PCH}_{221}$ triblock copolymer shows identical profiles.

All of the $\mathrm{PCH}_{X}-b-\mathrm{PtBA}_{147}-b-\mathrm{PCH}_{X}$ copolymers, synthesized from the $\mathrm{P}_{\mathrm{BA}} \mathrm{A}_{147}$ macroinitiator with intermediate molecular weight, exhibit well-defined first-order peaks at $10^{\circ} \mathrm{C}$. Figure $3(\mathrm{a})$ shows the $2 \mathrm{D}$ SAXS image at $10{ }^{\circ} \mathrm{C}$ after a first heating and cooling process for the $\mathrm{PCH}_{33}-b-\mathrm{PtBA}_{147}-b-\mathrm{PCH}_{33}$ copolymer, i.e., the triblock with the lowest $\mathrm{CH}$ block composition. This copolymer was synthesized by ATRP on purpose, using a concentration relationship of $[\mathrm{CH}] /[$ macroinitiator $]=200 / 1$, to obtain a lower molecular weight in the outer blocks and to examine the effect of this variable on the morphology. Concentric and uniform intensity rings ascribed to the first-order diffraction and several higher-orders are clearly observed in this figure, which indicates that the $\mathrm{PCH}_{33}-b-\mathrm{P} \mathrm{BA}_{147}-b$ $\mathrm{PCH}_{33}$ film exhibits a random microdomain orientation. Moreover, the $360^{\circ}$ azimuthal integration using the FIT2D a)

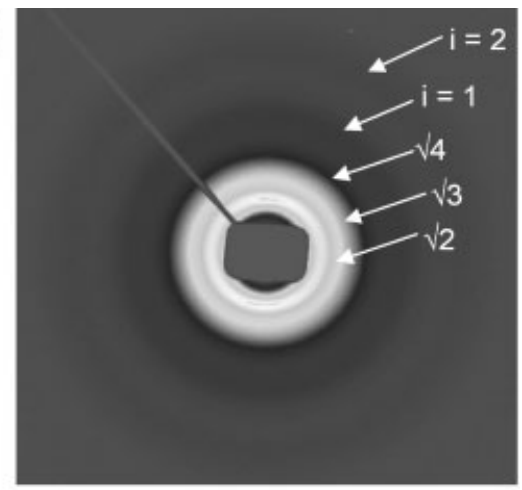

b)

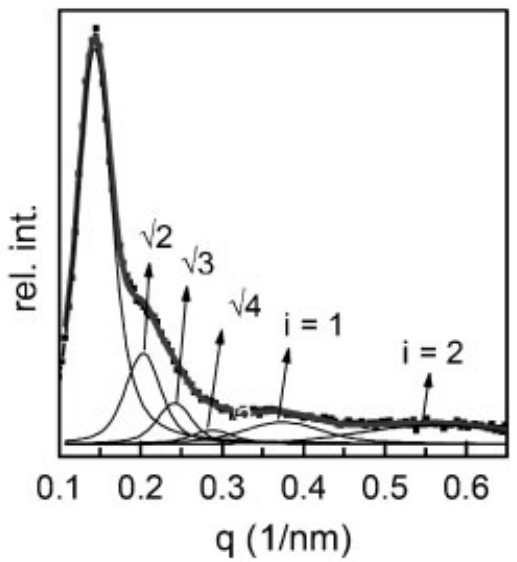

Figure 3. (a) SAXS-2D profile at $10^{\circ} \mathrm{C}$ for the $\mathrm{CH}_{33}-b-\mathrm{PtBA}_{147}-b$ $\mathrm{PCH}_{33}$ triblock copolymer. (b) $360^{\circ}$ azimuthally integrated 1D SAXS profile at $10^{\circ} \mathrm{C}$ and its corresponding decomposition into the different higher orders.

program, as mentioned in the Experimental Part, leads to the profile represented in Figure $3(b)$ that is identical to those obtained by using the linear detector and represented as a function of temperature in Figure 4. The high-order maxima at the peak position of $1: \sqrt{ } 2: \sqrt{ } 3: \sqrt{ } 4 \ldots$ relative to that of the first-order primary peak ${ }^{[2,3]}$ supports the assumption of a morphology based on $\mathrm{PCH}$ spherical microdomains within the PtBA matrix with a long-range spatial order for this copolymer, as seen in the upper 2D profiles in Figure 3, and after its decomposition into different Gaussian functions as shown in the lower plots of Figure 3. The arrows labeled $i(i=1-2)$ indicate the form factor scattering from the isolated spheres. Additional information might be obtained from its AFM image represented in Figure 5(a). The initial ordering of the annealed spin-coated film is defective and the $\mathrm{PCH}$ spherical microdomains seem to adopt a liquid-like arrangement within the matrix. ${ }^{[20]}$ However, this distorted morphology becomes more perfect after thermal treatment and seems to turn into a PCH body cubic centered (bcc) lattice.

The temperature-variable SAXS profiles depicted in Figure 4 show the above-mentioned ordering enhancement 

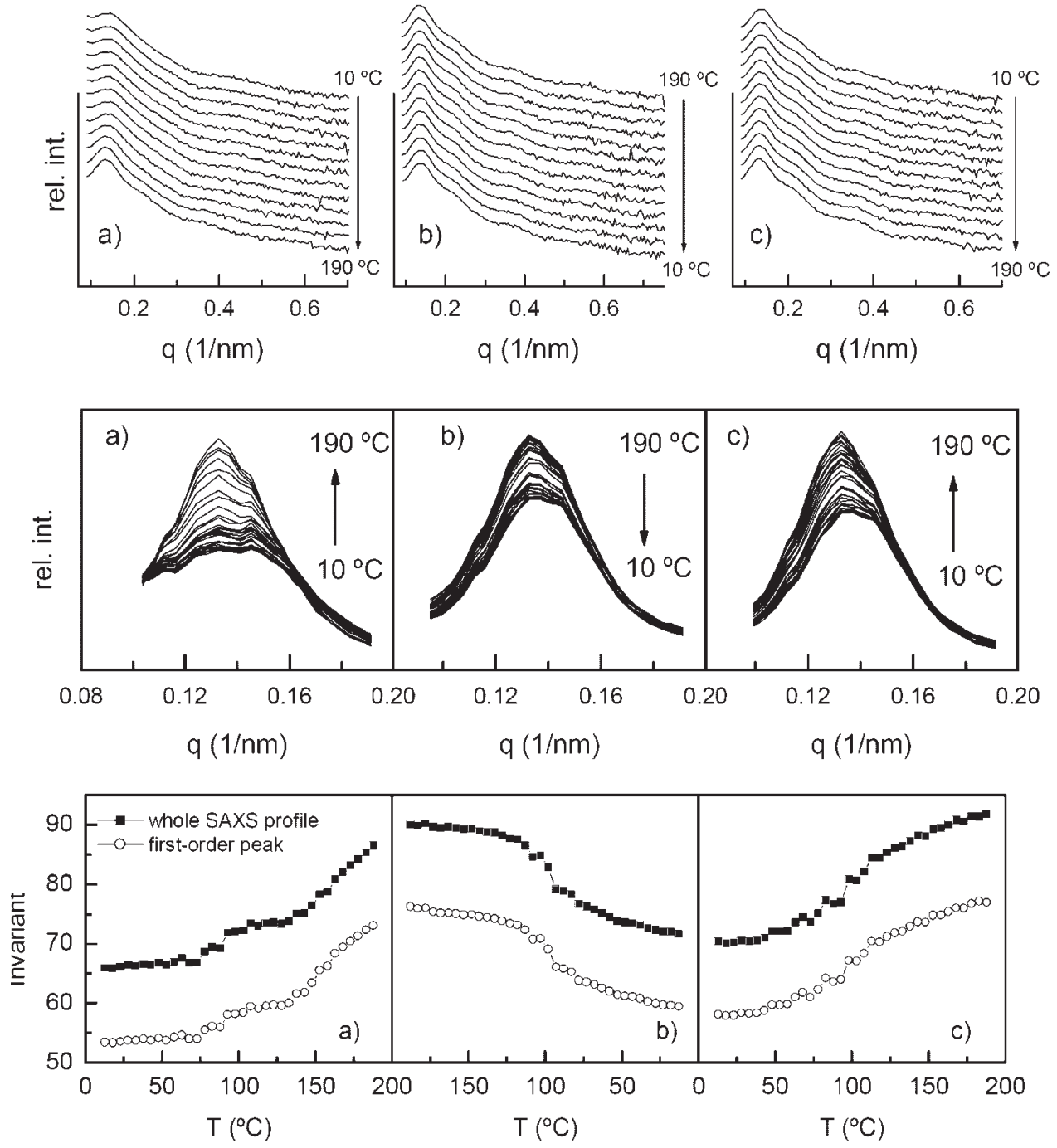

Figure 4. SAXS results for $\mathrm{PCH}_{33}-b-\mathrm{PtBA}_{147}-b-\mathrm{PCH}_{33}$ triblock copolymer: (a) first heating, (b) cooling, and (c) second heating. Upper plots: SAXS profiles as a function of scattering vector. Middle plots: Dependence of scattering vector on temperature for the first order peak. Bottom plots: Dependence of invariant on temperature.

through the first heating and the subsequent cooling. Accordingly, the intensity of the primary peak increases, its width decreases, and the high order reflections become more visible as the ordering proceeds, mainly during the first heating process, as represented in the middle plots of Figure 4 . The $q^{*}$ position of the primary peak maximum is shifted to lower values, i.e., to larger Bragg's spacing, which suggests a stretched chain conformation at higher temperatures during the first heating because of the evolution to a more ordered spherical arrangement. The variation of $q^{*}$ values is less considerable for cooling and the second heating, this being related to conformation changes that might take place when mobility varies down or up to the glass transition of the rigid blocks. These changes in mobility can be observed from a variation of the relative invariant ${ }^{[21]}$ estimated from the whole SAXS profile and exclusively from the $q^{*}$ first-order peak, as shown in the lower pictures of Figure 4 for the different thermal processes. The correlation is in agreement for both of them although the area is, as expected, sensibly less in the case when only the first order peak is considered. The invariant is defined as:

$$
\text { Invariant }=\int_{0}^{\infty} q^{2} I(q) \mathrm{d} q
$$

where $q$ is the scattering vector and $I(q)$ is the measured scattering intensity. The invariant gives an idea about the macroscopic electron density fluctuations. During the first heating, at a low temperature up to around $40^{\circ} \mathrm{C}$, the 
a)

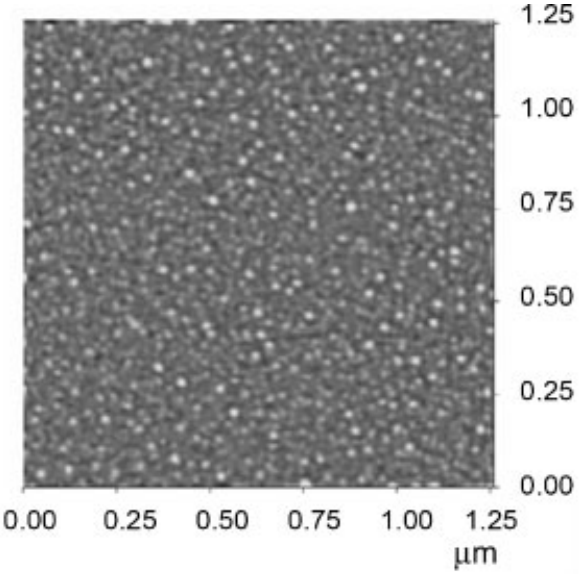

b)

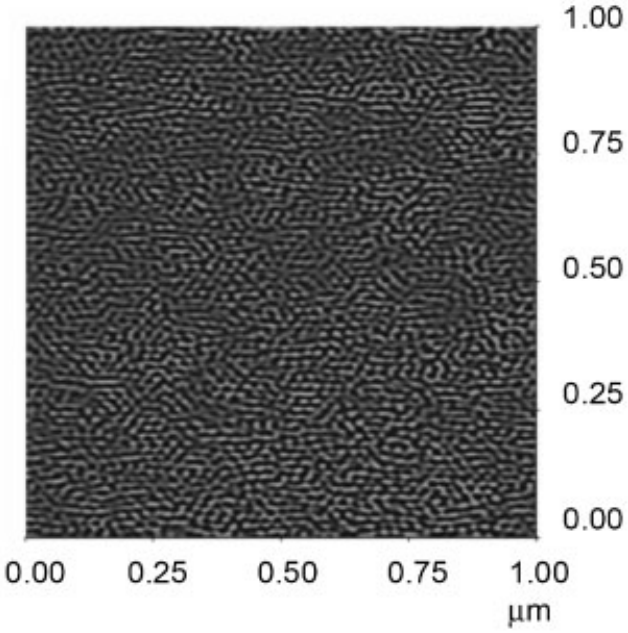

Figure 5. AFM height-image in tapping mode for the $\mathrm{CH}_{33}-b$ $\mathrm{PtBA}_{147^{-}}-b-\mathrm{PCH}_{33}$ triblock copolymer (a) and for the $\mathrm{PCH}_{123}-b$ $\mathrm{PtBA}_{147}-b-\mathrm{PCH}_{123}$ triblock copolymer (b).

invariant is kept practically unchanged while a considerable increase is observed above this temperature up to about $110^{\circ} \mathrm{C}$. The electron density fluctuation becomes higher as the overall mobility is raised beyond the glass transition temperatures of both the inner and outer blocks. At temperatures higher than $110^{\circ} \mathrm{C}$, significant microdomain reorganization and, consequently, ordering improvement of the initial morphology within the $\mathrm{PCH}_{33}-b-\mathrm{PtBA}_{147}-b-\mathrm{PCH}_{33}$ copolymer takes place. This morphological enhancement is correlated to the important invariant increase observed at high temperatures. As discussed for the $\mathrm{PCH}_{X}-b-\mathrm{P}_{\mathrm{BA}} \mathrm{A}_{107}-b-\mathrm{PCH}_{X}$ copolymers with the lowest molecular weight PtBA macroinitiator, an order-to-disorder transition is not observed for the $\mathrm{PCH}_{33}-b-\mathrm{PtBA}_{147}-b-\mathrm{PCH}_{33}$ copolymer over the temperature range analyzed. Therefore, the most important invariant changes found during the cooling and the second heating processes are those related to the glass transition of the a)

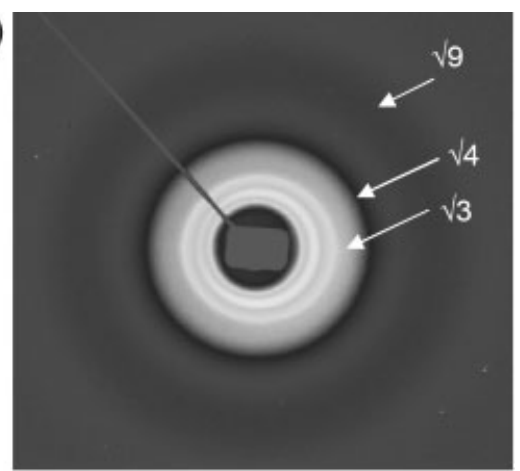

b)

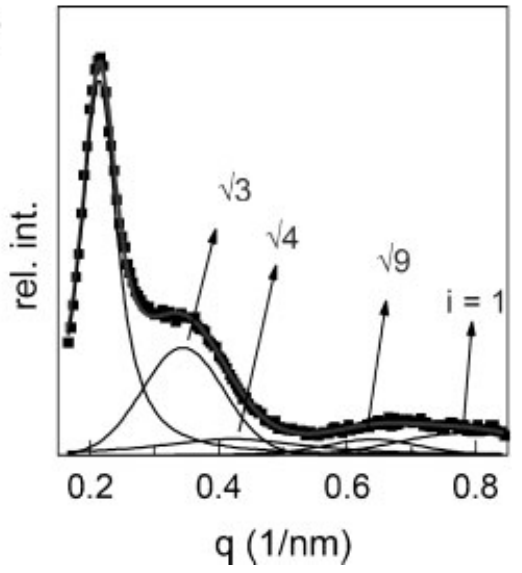

Figure 6. (a) SAXS-2D profile at $10{ }^{\circ} \mathrm{C}$ for the $\mathrm{PCH}_{123}-b-\mathrm{PtBA}_{147}-b$ $\mathrm{PCH}_{123}$ triblock copolymer. (b) $360^{\circ}$ azimuthally integrated $1 \mathrm{D}$ SAXS profile at $10^{\circ} \mathrm{C}$ and its corresponding decomposition into the different higher orders.

more rigid PCH blocks because of the great variation of mobility for the whole block copolymer.

The effect of an increase of PCH block molecular weight in the copolymers synthesized using the macroinitiator with an intermediate length is seen in Figure 6 for the $\mathrm{PCH}_{123}-b-\mathrm{PtBA}_{147}-b-\mathrm{PCH}_{123}$ triblock copolymer. This 2D SAXS image is rather different to that exhibited by the $\mathrm{PCH}_{33}-b-\mathrm{PtBA}_{147}-b-\mathrm{PCH}_{33}$ copolymer and presents multiple-order scattering maxima at peak positions of $1: \sqrt{ } 3: \sqrt{ } 4: \sqrt{ } 9$ relative to that of the first-order $q^{*}$ peak, as displayed directly from the 2D pattern and its decomposition into distinct high-order reflections after $360^{\circ}$ integration. These high-order reflections point out the development of microdomains with hexagonally packed PtBA cylinders, HEX ${ }^{\text {PtBA }}$, with long-range spatial arrangements. The AFM picture represented in the bottom of Figure 5 evidences this morphology, although it is also apparently defective in the initial spin-coated annealed cast film. Therefore, the scattering peak ascribed to the first order sharpens and intensifies during the first heating process in the temperature-variable experiments, as the temperature is raised mainly above the $T_{\mathrm{g}}^{\mathrm{CH}}$ (see the upper plot in Figure 7 for the whole profile and the middle plot for 

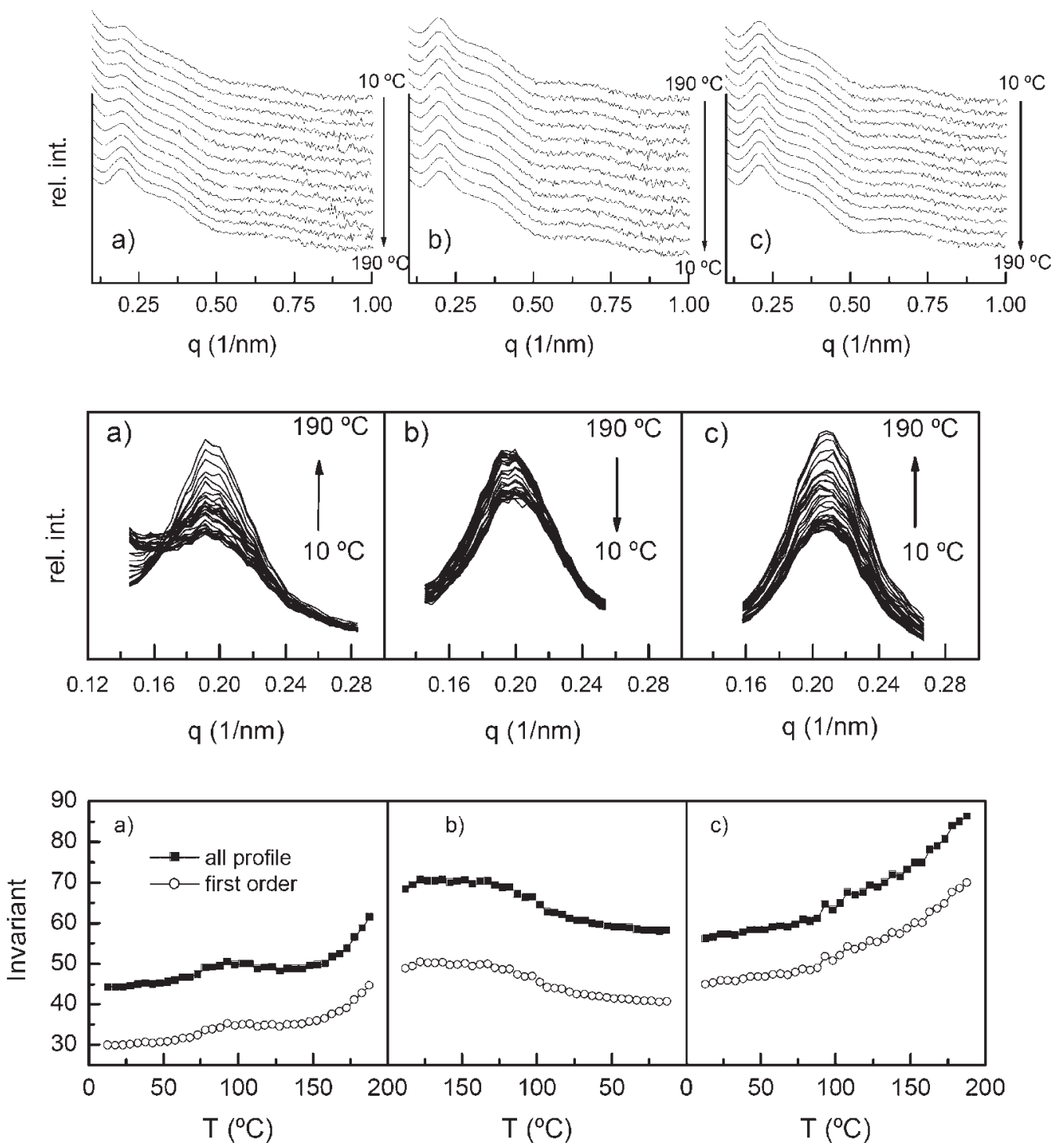

Figure 7. SAXS results for $\mathrm{PCH}_{123}-b$ - $\mathrm{PtBA}_{147}-b-\mathrm{PCH}_{123}$ triblock copolymer: (a) first heating, (b) cooling, and (c) second heating. Upper plots: SAXS profiles as a function of scattering vector. Middle plots: Dependence of scattering vector on temperature for the first order peak. Bottom plots: Dependence of invariant on temperature.

the primary peak). As mentioned previously, thermal treatments lead to an improvement of the original morphology. Invariant changes provide evidence, on the one hand, of such as enhancement and, on the other hand, of the mobility variations that exist below and above the corresponding glass transitions related to each block. An order-to-disorder transition is again not observed for this triblock copolymer in the temperature interval analyzed. Consequently, the effect of temperature on cooling and on a second heating is then less pronounced, and is ascribed to changes of mobility as depicted in the bottom plots in Figure 7.

The behavior of the rest of the $\mathrm{PCH}_{X}-b-\mathrm{PtBA}_{147}-b-\mathrm{PCH}_{X}$ copolymers, except for the $\mathrm{PCH}_{260}-b-\mathrm{PtBA}_{147}-b-\mathrm{PCH}_{260}$ copolymer, which has the highest PCH molecular weight, is similar to that just described for $\mathrm{PCH}_{123}-b-\mathrm{PtBA}_{147}-b$ $\mathrm{PCH}_{123}$, i.e., a hexagonally packed PtBA cylindrical morphology, HEX ${ }^{\text {PtBA }}$, with long-range spatial order that becomes more perfect after the application of the thermal treatments, is observed. However, although the $\mathrm{PCH}_{260}-b$ $\mathrm{PtBA}_{147}-b-\mathrm{PCH}_{260}$ final morphology is analogous to that mentioned, the intermediate development is quite different. Figure 8 (left upper picture) shows the initial nonexistence of an ordered arrangement of the different blocks in $\mathrm{PCH}_{260}-b-\mathrm{PtBA}_{147}-b-\mathrm{PCH}_{260}$. Therefore, no SAXS peak is detected from $10^{\circ} \mathrm{C}$ to $\approx 165^{\circ} \mathrm{C}$ and a monotonic diminishment of the intensity with $q$ is observed in the scattering profiles. However, different scatterings emerge 

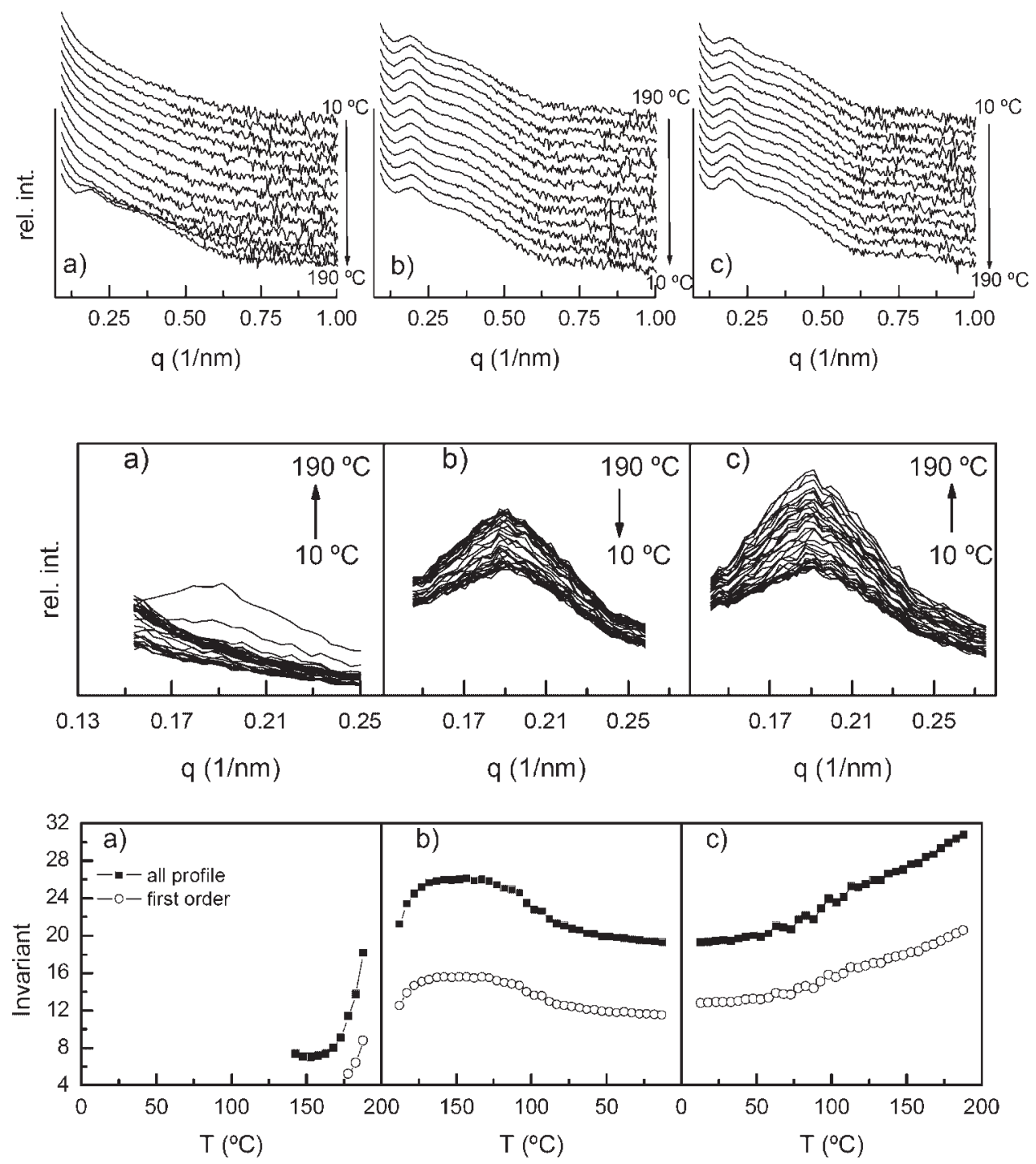

Figure 8. SAXS results for $\mathrm{PCH}_{260}-b-\mathrm{PtBA}_{147}-b-\mathrm{PCH}_{260}$ triblock copolymer: (a) first heating, (b) cooling, and (c) second heating. Upper plots: SAXS profiles as a function of scattering vector. Middle plots: Dependence of scattering vector on temperature for the first order peak. Bottom plots: Dependence of invariant on temperature.

above $165^{\circ} \mathrm{C}$, i.e., a disorder-to-order transition upon heating takes place, as seen from the appearance of a primary peak in the left middle picture of Figure 8. It is important to notice how sensitive the invariant is to detect the new arrangement that is occurring within this $\mathrm{PCH}_{260}-b-\mathrm{PtBA}_{147}-b-\mathrm{PCH}_{260}$ copolymer (left bottom picture), either the global invariant or that one only related to the first-order peak. This transition upon heating is not that usual in block copolymers. ${ }^{[12-17]}$ Generally, block copolymers undergo a disordered-to-order transition with decreasing temperature, ${ }^{[9]}$ which can also be termed an upper critical ordering transition (UCOT). This transition results from an increase in the interaction energy between the segments with decreasing temperature, as quantified by the Flory-Huggins segmental interaction parameter. However, years after, the discovery of a diblock copolymer that undergoes ordering upon heating revealed that the phase behavior of block copolymers was far richer than previously thought. ${ }^{[12]}$

No order-to-disorder transitions are found at higher temperatures, as observed for the rest of the block copolymers analyzed here. Coincident with the subsequent cooling and further heating processes, an improvement of the morphology developed upon the initial heating is observed. Therefore, the location of the $q^{*}$ first-order peak with increasing temperature during the second heating run is slightly shifted to lower values, i.e., to larger Bragg's spacing, which suggests a stretched chain conformation 


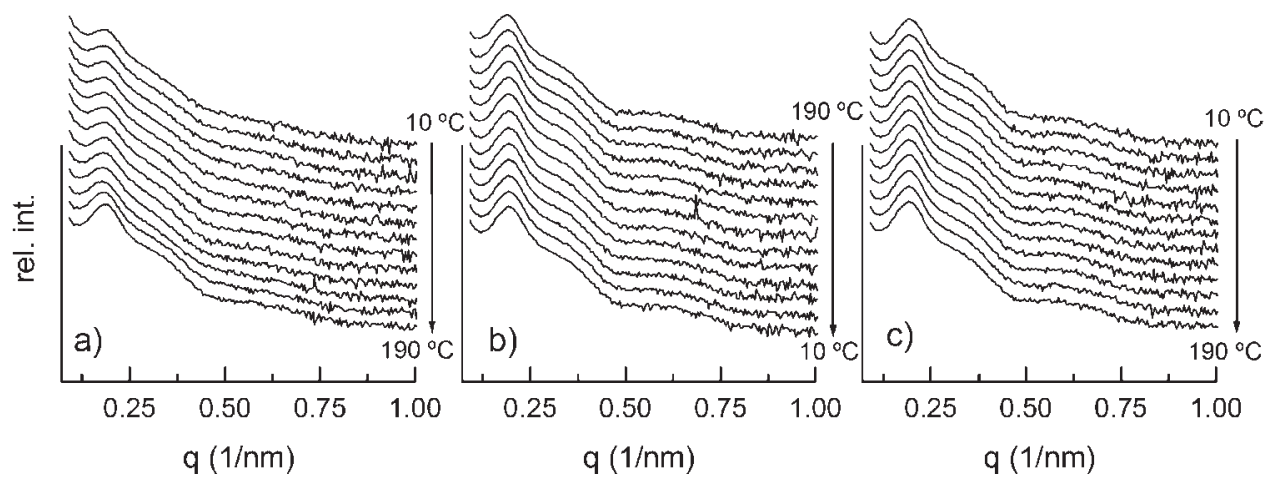

Figure 9. SAXS profiles of $\mathrm{PCH}_{174}-b-\mathrm{PtBA}_{213}-b-\mathrm{PCH}_{174}$ triblock copolymer: (a) first heating, (b) cooling, and (c) second heating.

associated with a more ordered state. In relation to the corresponding invariant pictures, the effect of the mobility of, mainly, the rigid blocks on the invariant values is noticeable.

The type of arrangement obtained is again estimated from the relative location of the multiple-order scattering maxima with respect to the first-order $q^{*}$ peak. The ratio
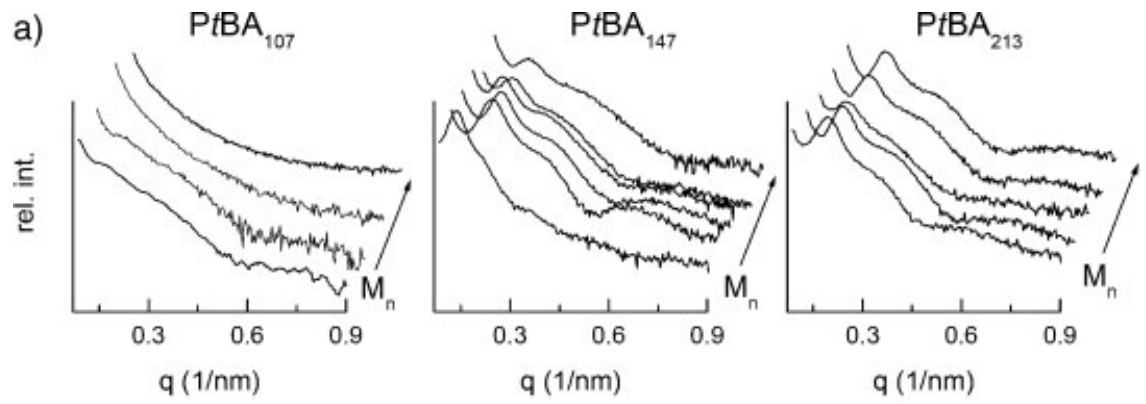

b)

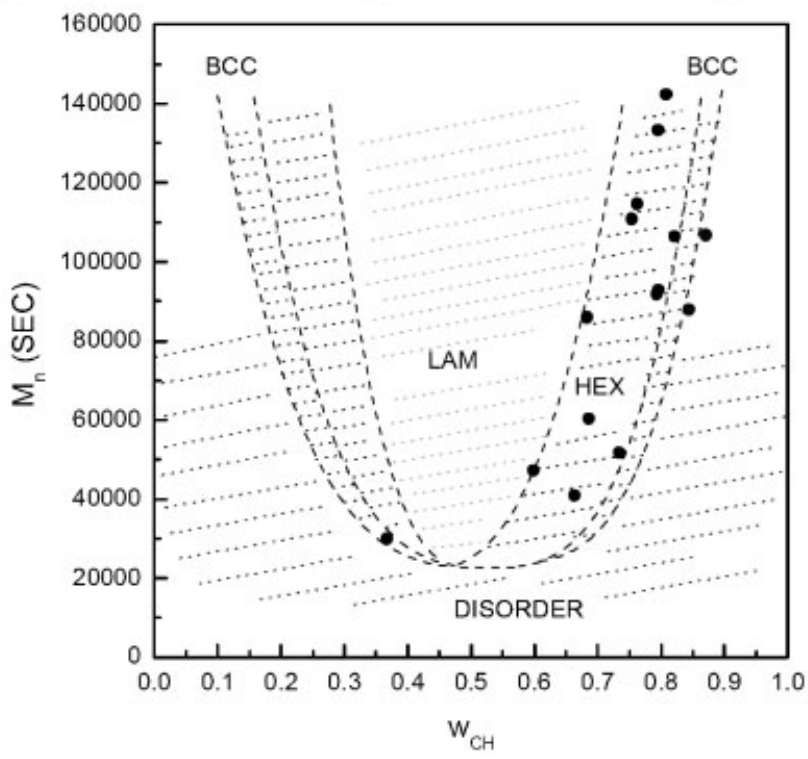

Figure 10. (a) SAXS profiles as a function of scattering vector at $10^{\circ} \mathrm{C}$ after a previous heating/ cooling cycle for all PCH-b-PtBA- $b$-PCH triblock copolymers. (b) Tentative phase diagram proposed for the PCH- $b$-PtBA- $b$-PCH triblock copolymers (represented as solid circles). calculated for the $\mathrm{PCH}_{260}-b-\mathrm{PtBA}_{147}-b-\mathrm{PCH}_{260}$ copolymer is $1: \sqrt{ } 3: \sqrt{ } 4: \sqrt{ } 9$, which indicates the development of microdomains with hexagonally packed PtBA cylinders, $\mathrm{HEX}^{\mathrm{PtBA}}$, with long-range spatial order, similar to the other $\mathrm{PCH}_{X}-b$ $\mathrm{PtBA}_{147}-b-\mathrm{PCH}_{X}$ copolymers synthesized with this intermediate molecular weight macroinitiator, except for $\mathrm{PCH}_{33}-b$ - $\mathrm{PtBA} \mathrm{B}_{147}-b-\mathrm{PCH}_{33}$ which presents $\mathrm{PCH}$ spheres as previously discussed.

Regarding the triblock copolymers obtained from the highest molecular weight $\mathrm{PtBA}_{213}$ macroinitiator, all of them exhibit a HEX morphology and behave analogously to the ABA copolymers already described with a similar arrangement, and an ordering enhancement with increasing temperature is observed, as depicted in Figure 9 for the $\mathrm{PCH}_{174}-b-\mathrm{PtBA}_{213}-b-\mathrm{PCH}_{174}$ triblock copolymer.

\section{Conclusion}

The ATRP-synthesized $\mathrm{PCH}_{X}-b$ PtBA $A_{Y} b-\mathrm{PCH}_{X}$ triblock copolymers show microdomain segregation as determined by WAXS and these domains are arranged to present an ordering at long range. Depending on inner block length and outer segment molecular weights, the initial ordering exhibited by the annealed films is, sometimes, rather defective. This feature might be ascribed to higher values of polydispersity associated with the synthetic method used compared to those obtained by anionic poly- 
merization. On the other hand, a significant ordering improvement is observed by effect of thermal treatment. Accordingly, from all of the results as a function of $\mathrm{PCH}$ molecular weight at a given PtBA macroinitiator summarized in the upper pictures of Figure 10, a tentative empirical phase diagram is proposed for these $\mathrm{PCH}_{X}-b-\mathrm{PAA}_{Y}-b-\mathrm{PCH}_{X}$ copolymers, as seen in the bottom plot of Figure 10 at the composition interval analyzed. In contrast to $A B$ diblock copolymers, the mean-field theory predictions point out an asymmetric phase diagram for ABA triblock copolymers as a result of the higher entropic penalty in deforming the central B segments to accommodate the two outer A blocks. ${ }^{[22,23]}$ Although non-theoretical predictions have been performed in this investigation, the experimental phase diagram is clearly asymmetric, being dominated by the lamellar phase, with smaller regions of hexagonally packed cylindrical and spherical phases, as expected. ${ }^{[23]}$ As can be seen, most of the block copolymers synthesized are found in a region with hexagonal PtBA cylinder arrangements, even the $\mathrm{PCH}_{260}-b-\mathrm{PtBA}_{147}-b-\mathrm{PCH}_{260}$ copolymer that exhibited the unusual disorder-to-order transition upon its first heating. On the other hand, the block copolymers with the highest compositions, $\mathrm{PCH}_{221}-b$ $\mathrm{P}_{\mathrm{BA}} \mathrm{B}_{107}-b-\mathrm{PCH}_{221}$ and $\mathrm{PCH}_{276}-b-\mathrm{PtBA}_{107}-b-\mathrm{PCH}_{276}$, present phase separation without ordering, while $\mathrm{PCH}$ spheres are attained for the $\mathrm{PCH}_{33}-b-\mathrm{PtBA}_{147}-b-\mathrm{PCH}_{33}$ copolymer. This small region ordered in spheres is in agreement with that stated, after introduction of fluctuation corrections, for the asymmetric phase diagrams in other triblock copolymers. $^{[24]}$

Acknowledgements: We acknowledge support of Ministerio de Educación y Ciencia (MAT2004-00496). The synchrotron work (in the A2 Soft Condensed Matter beamline of Hasylab at DESY, Hamburg, Germany) was supported by the European Community-Research Infrastructure Action under the FP6 'Structuring the European Research Area' Programme (through the Integrated Infrastructure Initiative 'Integrating Activity on Synchrotron and Free Electron Laser Science') (Contract RII3-CT-2004-506008). We thank the collaboration of the Hasylab personnel, especially Mr. M. Dommach and Dr. S. S. Funari.

Received: June 13, 2007; Revised: August 2, 2007; Accepted: August 3, 2007; DOI: 10.1002/macp.200700327
Keywords: disorder-to-order transition; hexagonally packed cylinders; $\mathrm{PCH}_{X}-b-\mathrm{P}_{\mathrm{BA}}-\mathrm{b}-\mathrm{PCH}_{X}$ triblock copolymers; SAXS; selfassembly

[1] S. Sakurai, Trends Polym. Sci. 1997, 5, 210.

[2] "Amphiphilic Block Copolymers. Self-Assembly and Applications", P. Alexandridis, B. Lindman, Eds., Elsevier Science B.V, Amsterdam 2000.

[3] "Block Copolymers. Synthetic Strategies, Physical Properties and Applications", N. Hadjichristidis, S. Pispas, G. A. Floudas, Eds., John Wiley \& Sons, Inc, Hoboken 2003.

[4] "Developments in Block Copolymer Science and Technology", I. Hamley, Ed., The Atrium, Southern Gate, Chichester 2004.

[5] "Controlled Radical Polymerization", Vol. 685, K. Matyjaszewski, Ed., American Chemical Society, Washington 1998.

[6] "Controlled Radical Polymerization: Progress in ATRP, NMP and RAFT", Vol. 768, K. Matyjaszewski, Ed., American Chemical Society, Washington 2000

[7] T. E. Patten, K. Matyjaszewski, Adv. Mater. 1998, 10, 901.

[8] K. Matyjaszewski, J. Xia, Chem. Rev. 2001, 101, 2921.

[9] L. Leibler, Macromolecules 1980, 13, 1602.

[10] G. H. Fredrickson, E. Helfand, J. Chem. Phys. 1987, 87, 697.

[11] F. S. Bates, J. H. Rosedale, G. H. Fredrickson, J. Chem. Phys. 1990, 92, 6255.

[12] T. P. Russell, T. E. Karis, Y. Gallot, A. M. Mayes, Nature 1994 368, 729.

[13] T. E. Karis, T. P. Russell, Y. Gallot, A. M. Mayes, Macromolecules 1995, 28, 1129

[14] A. V. G. Ruzette, P. Banerjee, A. M. Mayes, M. Pollard, T. P. Russell, R. Jerome, T. Slawecki, R. Hjelm, P. Thiyagarajan, Macromolecules 1998, 31, 8509.

[15] A. V. G. Ruzette, A. M. Mayes, Macromolecules 2001, 34, 1894

[16] A. V. G. Ruzette, P. Banerjee, A. M. Mayes, M. Pollard, T. P. Russell, J. Chem. Phys. 2001, 114, 8205.

[17] D. Y. Ryu, U. Jeong, D. H. Lee, J. Kim, H. S. Youn, J. K. Kim, Macromolecules 2003, 36, 2894.

[18] A. Muñoz-Bonilla, M. L. Cerrada, M. Fernández-García, J. Polym. Sci., Part A: Polym. Chem. 2005, 43, 4828.

[19] "X-ray Diffraction Procedures for Polycrystalline and Amorphous Materials", H. P. Klug, L. E. Alexander, Eds., Wiley, New York 1954, p. 632

[20] J. LaMonte Adams, D. J. Quiram, W. W. Graesley, R. A. Register Macromolecules 1996, 29, 2929.

[21] A. J. Ryan, J. L. Stanford, W. Bras, T. M. W. Nye, Polymer 1997 38, 759.

[22] A. M. Mayes, M. O. de la Cruz, J. Chem. Phys. 1989, 91, 7228.

[23] W. Wu, J. Y. Huang, S. J. Jia, T. Kowalewski, K. Matyjaszewski, T. Pakula, A. Gitsas, G. Floudas, Langmuir 2005, 21, 9721.

[24] A. M. Mayes, M. O. de la Cruz, J. Chem. Phys. 1991, 95, 4670. 